\title{
Does Resetting the Immune System Fix Multiple Sclerosis?
}

\author{
Gauruv Bose (i), Simon D. X. Thebault, Harold L. Atkins, Mark S. Freedman
}

\begin{abstract}
Multiple sclerosis is the leading non-traumatic cause of disability in young adults, affecting up to 100,000 Canadians. This chronic inflammatory and neurodegenerative disease of the central nervous system leads to irreversible neurologic disability if inadequately controlled. Though many current medications are available that reduce inflammatory damage, most patients continue to show some evidence of disease activity and accrue disability. In this review, we discuss the role of immune ablation followed by autologous hematopoietic stem cell transplantation (AHSCT), a therapeutic option for select patients with a more aggressive disease course. By "resetting" the immune system with a variety of ablative conditioning regimens, followed by immune reconstitution, this therapy has shown a durable response in halting evidence of inflammatory activity in most patients, without the need for continued disease-modifying therapies (DMT). Since the introduction of this therapy, there have been advances in patient selection and supportive care, such that morbidity has significantly declined and treatment-related mortality is minimized. Recent phase-II trials have shown excellent results in efficacy and safety of AHSCT; however, challenges exist which require ongoing study. The future challenges include comparing the variety of AHSCT conditioning regimens with each other as well as with existing highly effective DMT; identifying patients with an aggressive disease course through novel biomarkers who may benefit the most from AHSCT; and surveillance of longterm outcomes of different treatment protocols. In select patients, replacing the immune system with AHSCT holds promise of fundamentally altering the trajectory of their aggressive disease course.
\end{abstract}

RÉSUMÉ: Est-ce que le fait de réinitialiser le système immunitaire permet de guérir de la sclérose en plaques? La sclérose en plaques (SP) demeure la principale cause non-traumatique d'invalidité chez les jeunes adultes et affecte jusqu'à 100000 Canadiens. Cette maladie chronique neuro-dégénérative inflammatoire du système nerveux central entraîne une incapacité neurologique irréversible si elle n'est pas adéquatement contrôlée. Bien que de nombreux traitements médicaux permettent de réduire les dommages inflammatoires de la SP, on continue à observer chez la plupart des patients des signes d'activité de la maladie et une invalidité qui va en croissant. Dans cette étude, nous voulons discuter du rôle de la suppression immunitaire (immune ablation) suivie d'une greffe autologue de moelle osseuse (autologous hematopoietic stem cell transplantation ou AHSCT). Il s'agit ainsi d'une option thérapeutique pour certains patients dont l'évolution de la SP est davantage fulgurante. En « remettant à zéro » le système immunitaire des patients atteints de SP à l'aide de régimes de suppression de la réponse immunitaire, lesquels sont suivis ensuite par une reconstitution immunitaire, cette thérapie a pour effet de stopper l'activité inflammatoire chez la plupart d'entre eux sans qu'ils n'aient eu à entamer des thérapies continues modifiant le cours de la SP. À notre avis, cela constitue une réponse durable. Depuis l'introduction de cette thérapie, on a noté des avancées en ce qui regarde la sélection des patients et les soins prodigués, de sorte que les taux de morbidité ont diminué de façon notable et que la mortalité reliée aux traitements a été minimisée. De récents essais cliniques de phase II ont par ailleurs montré d'excellents résultats en matière d'efficacité et de sécurité. Cela dit, certains défis exigent des études supplémentaires : songeons, par exemple, à une comparaison entre les divers régimes de suppression de la réponse immunitaire et de greffe de moelle osseuse; au fait de comparer ces mêmes régimes à d'autres thérapies modificatrices de la maladie qu'on estime à l'heure actuelle très efficaces; à l'identification, au moyen de biomarqueurs novateurs, de patients dont l'évolution de la SP est davantage accélérée, patients qui pourraient le plus bénéficier d'une greffe de la moelle osseuse ; à la nécessité d'un suivi à long terme des différents protocoles de traitement et de leurs résultats. En somme, le fait de réinitialiser le système immunitaire de certains patients au moyen d'une greffe de moelle osseuse laisse entrevoir la possibilité de pouvoir modifier fondamentalement la trajectoire fulgurante de cette maladie.

Keywords: Multiple sclerosis, Hematopoietic stem cell transplantation, Neurology, Hematology

doi: $10.1017 / \operatorname{cjn} .2019 .294$

Can J Neurol Sci. 2020; 47: 1-10

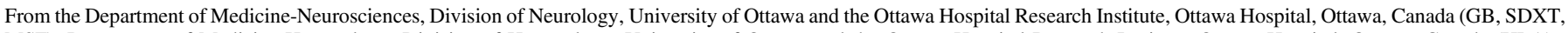

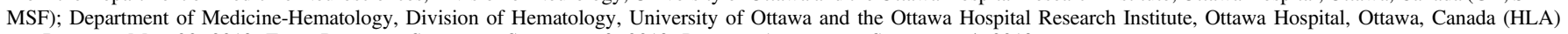
Received May 20, 2019. Final Revisions Submitted September 3, 2019. Date of Acceptance September 4, 2019.

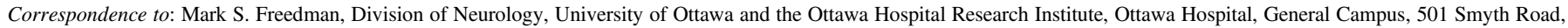
Box 601, Ottawa, ON K1H 8L6, Canada. Email: mfreedman@toh.ca 


\section{INTRODUCTION}

\section{The Journey of Multiple Sclerosis}

Multiple sclerosis (MS) is the most common autoimmune disease of the central nervous system (CNS), with over 2.5 million people affected worldwide. ${ }^{1}$ Canada is the country with the highest prevalence per capita, with 1 in 385 Canadians living with MS. ${ }^{2-5}$ Patients experience a myriad of disabling symptoms including fatigue, cognitive and mood disturbances, pain, visual changes, and mobility impairment from weakness and incoordination; all of which can have a dramatic impact on independence in over two-thirds of cases. ${ }^{6}$ The limitations on socialization, driving, and employment often reduce a patient's quality of life. ${ }^{7}$ The estimated total direct healthcare expenses are between $\$ 20,000$ and $\$ 78,000$ per person, with substantial indirect and intangible costs estimating over \$180-\$500 million in MS-related economic burden in Canada. ${ }^{8-11}$ Despite numerous available therapies, MS is the leading cause of disability from nontraumatic injuries in young adults. ${ }^{6}$ The recurrent inflammatory attacks of MS leads to increased disability, thus more utilization of healthcare resources. The need for halting disease activity for maintenance of individual neurologic function and quality of life, as well as reducing healthcare burden from MS, is crucial.

The course of MS is not the same for each patient. Up to $85 \%$ of patients present with clinical attacks that recover, partially or completely, and are deemed relapsing-remitting (RR), while other patients present with neurologic deficits that worsen over time through a degenerative, primary-progressive (PP) course. With either form of disease, there is damage that may not be appreciated, with the magnetic resonance imaging (MRI) showing a considerable amount of "silent" inflammatory T2 or gadolinium-enhancing lesions. In fact, lesions on MRI may appear some time before any symptoms or signs develop in patients. This phase is coined the radiologically isolated syndrome and confers up to $30 \%$ conversion to RRMS or PPMS at 5 years. ${ }^{12}$ The diagnosis of MS has been revised by the McDonald Criteria in 2017. Importantly, RRMS can be made after one clinical neurologic event if there is radiologic evidence of lesions in different regions of the CNS that exhibit dissemination in time by gadolinium enhancement of a proportion of lesions or by presence of oligoclonal bands in cerebrospinal fluid (CSF). ${ }^{13,14}$ Otherwise, if on follow-up new T2 or enhancing lesions appear on MRI, or if the patient experiences a new clinical event, RRMS can be diagnosed. If the patient experiences ongoing progression of disabilities for 1 year and has a typical MRI showing two or more spinal cord lesions and one or more symptomatic lesions in the brain, or oligoclonal bands with either brain or spinal lesions, a diagnosis of PPMS can be made. Making the diagnosis of MS early is important, as therapeutic intervention prior to accrual of inflammatory damage has the best outcomes.

The goal of treatment in MS is to prevent radiologic and clinical events, or relapses, that occur primarily through inflammatory mechanisms, in hopes to prevent disease progression. At an unknown threshold, inflammation can lead to axonal loss and neurodegeneration, which represents irreversible damage of the nervous system and is probably the substrate of progression. Patients manifest this neurodegeneration clinically by developing worsening neurologic symptoms in lieu of inflammatory evidence on MRI; these patients are felt to have evolved to the secondary-progressive (SP) phase of their disease. ${ }^{15,16}$ Traditionally, validated examination markers, such as the Expanded
Disability Status Scale (EDSS) and the timed 25-foot walk component of the Multiple Sclerosis Functional Composite, are used to quantitatively estimate and track a patient's disease progression. ${ }^{17-20}$ Without treatment, up to $50 \%$ of patients with RRMS transition to SPMS, and in 25 years, as high as $90 \%$ of patients have been reported to transition. ${ }^{21-23}$ There is evidence of axonal loss even at the time of the first attack, illustrating the need for early effective treatment to limit the buildup of axonal loss and thus alter the natural history of disease. ${ }^{24,25}$

\section{The Need for Highly Effective Disease-Modifying Therapies}

The severity of disease in a patient with MS is varied, and a proportion of patients have particularly difficult to treat disease and are referred to as having aggressive MS. Patients denoted as having aggressive MS have frequent relapses with little time to repair in-between, often accumulating disability rapidly, making disability progression inevitable. These patients also have ongoing disease activity that is a challenge to control by diseasemodifying therapies (DMT), particularly first-line agents, and these patients typically have a poorer prognosis. ${ }^{26}$ The rapidity with which attacks result in accumulation of disability is the most obvious feature of patients that are clinically defined as having aggressive MS. ${ }^{27}$ These patients can transition to the progressive form of the disease earlier and have been reported to often be more disabled. ${ }^{27}$ The proportion of patients with the aggressive form of the disease is estimated to be between $4 \%$ and $14 \% .^{25}$ Proposed criteria for its definition include patients with RRMS who develop an EDSS greater than 4.0 (disability causing limitation of their daily activities) within 5 years or continued clinical or radiographic relapses despite a year of therapy. ${ }^{28,29}$ There are new biomarkers being studied to assist in the prediction of patients with aggressive MS including neurofilament light chain (NfL), a measure of axonal destruction, with higher baseline levels associated with higher 10-year brain atrophy and disability. ${ }^{30}$ Other poor prognostic factors less clearly defined but understood to increase risk of transition to SPMS despite therapy are advanced age, male gender, non-Caucasian ethnic background, smoking, and multifocal relapses. ${ }^{28}$ For these patients, early, aggressive therapy is indicated to prevent or delay transition to SPMS and maintain a person's independence. ${ }^{31}$

Therapeutic clinical trials in MS are often designed to compare a new putative DMT with either first-line agents or, rarely, placebo. The primary outcome of these trials have typically been a reduction of inflammatory activity as evidence by MRI lesions or reduced relapse rate, often described as the annualized relapse rate (ARR). First-line agents, such as injectable interferon beta or glatiramer acetate, achieve a reduction in ARR by $30-40 \%$ relative to placebo, while the newer more potent DMT, such as monoclonal antibody infusions, achieve an ARR of up to $50 \%$ compared with first-line agents as well as relative reductions of MRI activity of $90 \%$ or more. ${ }^{32}$ Despite these improvements in efficacy, these trials indicate that patients have ongoing inflammatory damage even with new high-potency DMT. As the disease advances, relapses become less clinically or radiologically evident, yet worsening of disability continues as noted by increasing EDSS or reduced social well-being, such as loss of employment or driving.

Neurologists and patients are now at a point where increased understanding of the underlying pathophysiology is changing 
how we treat the disease. ${ }^{33}$ The traditional approach to treatment of MS is to first initiate lower efficacy, but safer, DMT until a patient shows signs of ongoing disease activity before "escalating" to more efficacious option. Increasingly, higher efficacy DMTs are being used first for patients felt to have more aggressive disease. The goal of completely halting the early inflammatory phase with more potent DMT can fundamentally alter a given patient's disease trajectory. ${ }^{24}$ A patient who has no new MRI lesions, clinical relapses, or worsening of EDSS scores over time is said to have no evidence of disease activity (NEDA): this is the new therapeutic target of highly effective therapies. ${ }^{34,35}$

The highest rates of NEDA are achieved with autologous hematopoietic stem cell transplantation (AHSCT), up to $83 \%$ in the first 2 years. ${ }^{36}$ AHSCT is a relatively complex and varied procedure that has the potential to expose patients to considerable risk. The purpose of this review is to investigate the current evidence on efficacy and safety of AHSCT.

\section{Resetting the Immune System with Autologous Hematopoietic Stem Cell Transplantation \\ Overview of Autologous Hematopoietic Stem Cell Transplantation}

High-intensity chemotherapy followed by AHSCT is a wellestablished treatment for lymphoma and multiple myeloma. Interest and refinement of the procedure has grown since the first patient underwent a similar procedure for MS in the 1990s. ${ }^{37,38}$ The procedure has become increasingly safe with modification of the dose intensity and supportive care, as well as improved patient selection. Patient selection involves consideration of their disease history, as well as their comorbidity and demographic profile. Patients treated with hematopoietic stem cell transplants for hematologic malignancies have provided data on concerning comorbidities such as solid organ tumor, valvular heart disease, severe pulmonary or hepatic disease can increase the risk of adverse events. ${ }^{39,40}$ In patients with aggressive MS, who have failed standard DMT and may otherwise become significantly disabled, AHSCT may result in a therapeutic response and thus be offered as a treatment option. ${ }^{41}$ The procedure is complex and requires an accredited center with specialist expertise in hematopoietic stem cell transplantation, preferably with experience in AHSCT for autoimmune diseases, as well as a comprehensive care team with intensive care level facilities. ${ }^{42}$ In the acute setting, pancytopenia requiring transfusion support, gastrointestinal side effects causing nausea or diarrhea, as well as constipation as a side effect of supportive medications such as anti-emetics, and light-headedness are common, while serious acute complications such as sepsis, liver toxicity, bony pain crises, and pericarditis are less common; while late complications include premature menopause and infertility for women, secondary autoimmunity and an increased risk of malignancy of up to 1.4 times that of the general population. ${ }^{43,44}$ For this reason, a highly specialized multidisciplinary team of neurologists and hematologists is necessary; both requiring an understanding of the patients most likely to benefit from the procedure as well as to be vigilant for complications.

Prior to 2016, there were over 800 patients with MS reported to have undergone AHSCT which highlighted several key points: lower age at transplant and EDSS at baseline were associated with fewer adverse events, better disability outcomes, and overall less morbidity and mortality. ${ }^{45,46}$ More recently, several prospective series were reported, each using a slightly different AHSCT protocol with favorable yet not identical efficacy. ${ }^{47-53}$ Differences in cell mobilization, conditioning regimens, and stem cell selection techniques, as well as using different patient populations make it difficult to draw uniform conclusions. It is difficult, therefore, to compare across the respective outcomes in terms of efficacy, with now nearly similar safety profiles. Long-term safety, however, remains to be established.

\section{The Autologous Hematopoietic Stem Cell Transplantation Protocol}

The procedure begins by identifying a patient with aggressive MS, who has radiologic or clinical relapses despite 1 year of treatment with DMT or who has EDSS progression to 4.0 or more within 5 years, and a demographic and comorbidity profile that allows them a chance to overcome the potential toxicity of AHSCT. The overall procedure for AHSCT consists, firstly, of a mobilization procedure to release a patient's CD34-positive hematopoietic stem cells into their peripheral circulation where they can be extracted and stored, followed by a conditioning regimen of chemotherapeutic and antibody agents to ablate the patient's autoreactive immune system, and finally re-infusion of the patient's stored autologous hematopoietic stem cells to reconstitute an immune system without autoreactivity. Supportive management is required to mitigate the effects of the chemotherapy. The regimen used for stem cell mobilization, collection, selection, and transplantation by our program has previously been published (Figure 1). ${ }^{50,54}$

During the mobilization phase, the patient's own hematopoietic stem cells are mobilized from the bone marrow into the circulation using a combination granulocyte colony-stimulating factor (G-CSF), also known as filgrastim, with or without the concurrent use of cyclophosphamide (CP). CP increases the efficiency of stem cell mobilization and will provide partial immune depletion that mitigates the risk of G-CSF-induced immune activation causing a relapse. ${ }^{55,56}$ The extraction of hematopoietic stem cells may be directly obtained through bone marrow aspiration; however, mobilization techniques allow peripheral leucopheresis to produce a hematopoietic stem cell graft from the patient's blood. ${ }^{57}$ Certain groups remove immune cells that contaminate the hematopoietic stem cell graft by selecting CD34-positive cells using immunomagnetic cell separation technology to reduce the burden of potentially autoreactive cells reintroduced into the patient. Magnetic bead-bound antibodies to CD34 (a marker of early stem cells) are added to the graft, which is then passed through a magnetic field. Cells bound to the beads, expressive CD34, are retained and the non-CD34 expressing cells are washed away. The magnetic field is removed and the CD34-purified hematopoietic progenitor and stem cells are collected. This procedure requires a specialized clinical-scale device, such as the Miltenyi CliniMACS at the stem cell lab facility. The collected hematopoietic stem cell graft, whether unselected or processed, is cryopreserved and stored until required for AHSCT.

The transplant phase occurs subsequently beginning with the administration of a conditioning regimen that uses high-dose chemotherapeutic medications and lymphocyte-depleting antibodies to ablate the patient's immune system. There is an ongoing 
A

Hematopoietic Stem Cell Graft Mobilization and Collection
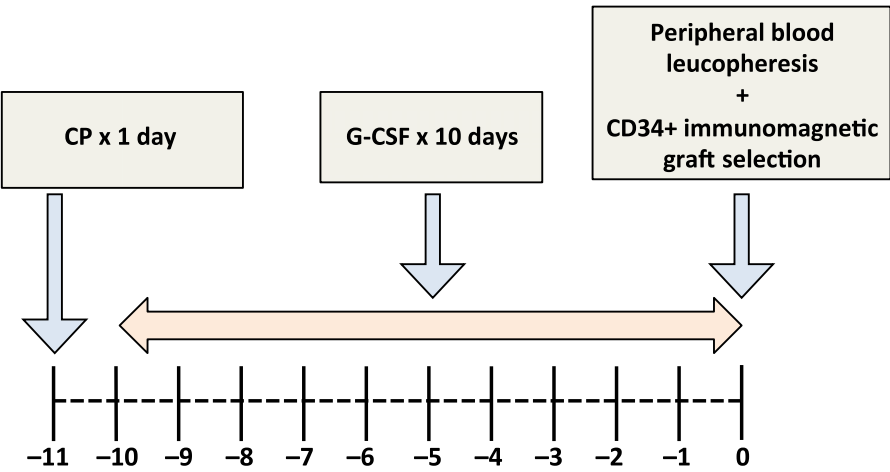

graft selection

B

Conditioning, Stem Cell Transplantation, and Supportive Care

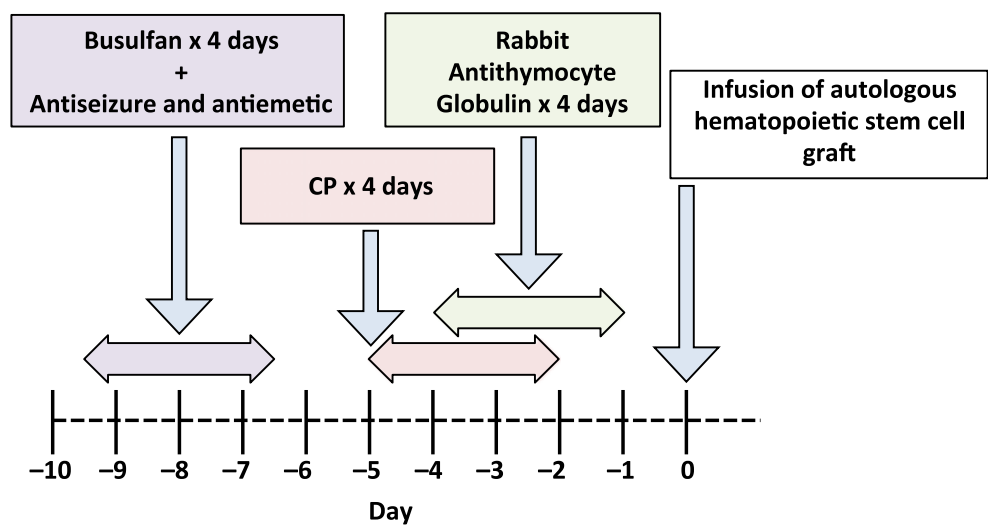

Supportive care: Vital signs, serology and urinalysis

- Ursodiol TiD for SOS prophylaxis from day-11 to day+90

- rHG-CSF daily for neutrophil recovery augmentation from day-0 to day+11

- Fluconazole daily for fungal prophylaxis from day-4 to day+100

- TMP/SMX daily for Pneumocystis carinii prophylaxis from day-0 to day+365

- IVGG for passive immunity, weekly from day-0 to day+28 then monthly from day+56 to day +365

- Valacyclovir TiD for viral prophylaxis from day-4 to day+100 then BiD for 6 months

Figure 1: Schematic of autologous hematopoietic stem cell transplant procedure performed in the Canadian AHSCT study (50,54). (A) Initial hematopoietic stem cell graft mobilization and collection. (B) Subsequent conditioning regimen and stem cell transplantation, along with supportive care. $C P=$ cyclophosphamide; $G-C S F=$ granulocyte colony-stimulating factor; SOS = sinusoid occlusive syndrome; $A U C=$ area under the curve; $r H G-C S F=$ recombinant human $G-C S F ; T M P / S M X=$ Trimethoprim/sulfamethoxazole; IVGG=Intravenous gamma globulin.

debate regarding the optimal conditioning regimen to use recognizing that each regimen may offer a risk: benefit ratio that is appropriate for different patient population. The intensity of the conditioning regimen can be varied by altering the number and types of agents used along with their doses. Higher intensity regimens result in greater immune depletion and off-target toxicity. ${ }^{58}$ Certain drugs, such as busulfan, cross the blood-brain barrier efficiently and target the local CNS immune system resulting in a more durable response, however, with a possible increased risk of acute adverse events. ${ }^{45}$ High-intensity regimens that included total body irradiation have not been widely used since the mid-2000s. ${ }^{59,60}$ A regimen containing bis-chloroethylnitrosourea also known as carmustine, etoposide, ara-C also known as cytosine arabinoside or cytarabine, and melphalan (BEAM), results in a durable NEDA response with a $3-4 \%$ treatment-related mortality (TRM). Lower intensity regimens combine CP with antithymocyte globulin (ATG), or even alemtuzumab for conditioning, and result in less regimen-related toxicity although potentially higher rates of breakthrough disease activity. ${ }^{49}$ Regimen-related morbidity is extremely low in the MS population receiving this regimen but deaths have been reported in other populations receiving this combination. ${ }^{61}$ The variation among AHSCT protocols is one of the challenges in comparing results from multiple centers.

Following the conditioning regimen, the previously cryopreserved autologous hematopoietic stem cell graft is thawed and 
intravenously infused back into the patient. G-CSF is administered following transplantation to enhance the speed of myeloid recovery. It has been shown that this combination of conditioning, along with the autologous hematopoietic graft transplant, is more effective than either alone. ${ }^{62,63}$

Patients undergoing AHSCT require supportive care during and after the administration of cytotoxic chemotherapy. Some supportive care measures are the use of potent antiemetic prophylaxis, hyperhydration by isotonic crystalloid with or without infusion of sodium 2-mercaptoethane sulfonate to minimize the risk of hemorrhagic cystitis from $\mathrm{CP}$, blood product transfusion to mitigate anemia and thrombocytopenia, pain medication for mucositis or enteritis, antidiarrheals, nutritional supplements, infection prophylaxis against fungal, viral, and bacterial pathogens, and passive immunity provision with prophylactic intravenous gamma globulin. Physiotherapy is an important adjunct during the acute period following transplantation as fever or other metabolic stress can result in pseudoflares of MS activity. Prophylaxis with ursodiol is used in patients receiving busulfan and $\mathrm{CP}$-containing regimens to prevent sinusoid obstruction syndrome (SOS), an uncommon complication that, in its most severe form, can cause a capillary leak syndrome with hepatomegaly, renal and respiratory failure, and even death. Immune reconstitution occurs over the first 6-12 months after AHSCT. During this time, prophylaxis is provided against shingles and Pneumocystis carinii. Routine re-immunization is started 6-12 months after AHSCT as preexisting immunity to vaccines is either attenuated or eliminated by the transplantation. Generally, immunization with a live vaccine, such as measles, mumps, rubella, is deferred until 2 years after AHSCT. Follow-up after AHSCT should include monitoring for secondary autoimmunity, such as thyroid dysfunction or immune-mediated thrombocytopenia, as well as for other late complications.

\section{Efficacy and Safety of Autologous Hematopoietic Stem Cell Transplantation}

There are multiple centers internationally that have reported their experience in AHSCT for MS. Compared to even the most efficacious monoclonal antibodies, which obtain rates of NEDA at 2 years of nearly $50 \%{ }^{64}$, the lowest rate of NEDA for AHSCT protocol at 2 years was over $70 \%^{51}$. A major focus of many AHSCT trials is on safety, since this treatment has potential for immediate toxic side effects and even TRM, while the natural history of MS is that disability and eventual mortality from complications of immobility such as pneumonia or urosepsis from indwelling catheters is an infrequent immediate consequence. Furthermore, currently approved DMTs have welldefined safety profiles.

There have been two randomized trials investigating the effect of AHSCT in aggressive MS compared with conventional therapies. The first randomized phase-II trial was published in 2015 by Mancardi et al. Twenty-one patients with EDSS progression and gadolinium-enhancing lesion on MRI despite prior treatment with injectable DMT, or azathioprine, CP, and methotrexate, in different combinations, were randomized to either received mitoxantrone, an anthracenedione used primarily to treat hematologic and certain solid organ cancers, or AHSCT following BEAM conditioning. ${ }^{65}$ The ARR was 0.19 events per year in the AHSCT group compared to 0.6 events per year in the mitoxantrone group. Though these numbers were small, and follow-up data were incomplete over the 4-year period, it highlighted that though four patients in the AHSCT arm had severe adverse events, there was no TRM. Interestingly, in the AHSCT arm, approximately half of the patients were classified as SPMS yet showed similar rates of EDSS progression as the RRMS patients, of approximately $50 \%$ in each group. A second, larger randomized study is the Multiple Sclerosis International Stem cell Transplant trial by Burt et al. ${ }^{52}$ This trial compared the rate of progression between 55 randomized patients treated with AHSCT following a CP with ATG conditioning regimen, and 55 treating physician prescribed DMT, almost half of which received natalizumab, but did not include the newer potent monoclonal antibody DMTs alemtuzumab or ocrelizumab. They all had to have high disease activity in the last year, despite DMT that mostly included interferon beta and glatiramer acetate. The study reported no TRM, which showed significantly reduced evidence of ongoing disease activity at a median 2-year follow-up, with only three patients $(6 \%)$ in the AHSCT arm showing a clinical relapse, compared to 30 patients $(60 \%)$ in the control arm. Out of 21 patients randomized to DMT who received natalizumab, $42 \%$ had a relapse at 6 months and $69 \%$ at 1 year. This is an unusually high rate of relapse and would warrant further explanation or study.

A pooled analysis by Muraro et al. in 2017 included data from two international registries of hematopoietic cell therapy: the North-American-based Center for International Blood \& Marrow Transplant Research and the European Group for Blood and Marrow Transplantation. This meta-analysis summarized data on 281 patients with MS followed for a median 6.6 years. ${ }^{66}$ Progression as measured by EDSS after AHSCT was associated with older age, PPMS or SPMS, and three or more prior treatments. However, this analysis did not specifically investigate NEDA. Over the follow-up period, 37 patients died, with $8(2.8 \%)$ succumbing within 100 days of AHSCT due to transplantation-related causes. Of these eight patients, none had a CP plus ATG conditioning regimen.

Acute regimen-related mortality has been seen among groups of patients receiving other conditioning regimens. Out of 28 patients who received total body irradiation, one patient $(4 \%)$ passed away 2 months posttransplant from Epstein-Barr virus associated lymphoproliferative disorder, a complication of immunosuppression. ${ }^{59}$ One patient out of $24(4 \%)$ who received a busulfan-containing regimen passed away 2 months posttransplant from SOS, reported in $2016 .^{50}$ After investigation of this adverse event, dose reduction of busulfan was implemented and no further mortality has occurred in the next 56 consecutive MS patients who received a busulfan-containing regimen at our center. Out of the 149 patients treated with a BEAM conditioning regimen, 6 patients $(4 \%)$ passed away within 100 days of transplant. These recent studies highlight the comparable rate of significant adverse events with busulfan-containing and BEAM conditioning regimens. Differences in patient selection, conditioning, graft manipulation, and variable lengths of follow-up all make it difficult to come out with definitive conclusions regarding the best regimen to use.

\section{Comparing Autologous Hematopoietic Stem Cell Transplantation Protocols}

Attempting to compare the outcomes of AHSCT trials is challenging. In the past 10 years, seven cohorts of patients who underwent AHSCT were published (Table 1). ${ }^{47-53,67}$ The patients 
Table 1: Safety and efficacy of autologous hematopoietic stem cell transplantation protocols in the last 10 years

\begin{tabular}{|c|c|c|c|c|c|c|c|c|c|c|c|c|c|c|}
\hline \multirow{2}{*}{$\begin{array}{l}\text { Study } \\
\text { (reference) }\end{array}$} & \multicolumn{5}{|c|}{ Baseline demographics } & \multicolumn{3}{|c|}{ Protocol } & \multicolumn{6}{|c|}{ Outcomes } \\
\hline & $\mathbf{N}$ & $\begin{array}{l}\text { Age, mean, } \\
\text { year }\end{array}$ & $\begin{array}{c}\text { MS } \\
\text { duration, } \\
\text { mean, year }\end{array}$ & RRMS (\%) & $\begin{array}{l}\text { Baseline } \\
\text { EDSS } \\
\text { (mean) }\end{array}$ & $\begin{array}{c}\text { Graft } \\
\text { mobilization }\end{array}$ & $\begin{array}{c}\text { Graft } \\
\text { processing }\end{array}$ & $\begin{array}{l}\text { Conditioning } \\
\text { regimen }(\mathrm{N})\end{array}$ & $\begin{array}{c}\text { Follow-up } \\
\text { (median, } \\
\text { year) }\end{array}$ & $\begin{array}{l}\text { TRM, } \\
\text { N }(\%)\end{array}$ & $\begin{array}{c}\text { RFS, } \\
(\%)\end{array}$ & $\begin{array}{c}\text { MRI-FS } \\
(\%)\end{array}$ & $\begin{array}{c}\text { EDSS-FS } \\
(\%)\end{array}$ & $\begin{array}{c}\text { NEDA } \\
(\%)\end{array}$ \\
\hline $\begin{array}{l}\text { Shevchenko } \\
\text { et al. } 2012^{47}\end{array}$ & 95 & 34 & 5.0 & 46 & 3.5 & G-CSF & None & \begin{tabular}{|c|} 
BM (60) Mini- \\
BEAM-ATG (39)
\end{tabular} & 4.1 & $0(0)$ & 85 & 82 & 82 & 80 \\
\hline $\begin{array}{l}\text { Burman et al. } \\
2014^{48}\end{array}$ & 41 & 31 & 6.3 & 85 & 6.0 & $\mathrm{CP}+\mathrm{G}-\mathrm{CSF}$ & None & $\begin{array}{c}\text { BEAM-ATG (34) } \\
\text { CP-ATG (7) }\end{array}$ & 4.0 & $0(0)$ & 87 & 85 & 77 & 68 \\
\hline $\begin{array}{l}\text { Burt et al. } \\
2015^{49}\end{array}$ & 151 & 37 & 5.1 & 81 & 4.0 & $\mathrm{CP}+\mathrm{G}-\mathrm{CSF}$ & None & $\begin{array}{l}\text { CP-ATG (129) } \\
\text { CP-Alem (22) }\end{array}$ & 2.0 & $0(0)$ & 80 & NA & 87 & 68 \\
\hline $\begin{array}{l}\text { Atkins et al. } \\
2016^{50}\end{array}$ & 24 & 34 & 7.5 & 50 & 5.0 & $\mathrm{CP}+\mathrm{G}-\mathrm{CSF}$ & CD34 + IMS & BU-CP-ATG (24) & 6.7 & $1(4)$ & 100 & 100 & 70 & 70 \\
\hline $\begin{array}{r}\text { Nash et al. } \\
2017^{51,67}\end{array}$ & 24 & 37 & 4.9 & 100 & 4.5 & G-CSF & CD34 + IMS & BEAM-ATG (24) & 5.0 & $0(0)$ & 87 & 86 & 91 & 69 \\
\hline $\begin{array}{l}\text { Burt et al. } \\
2019^{52}\end{array}$ & 52 & 36 & 5.3 & 100 & 3.4 & $\mathrm{CP}+\mathrm{G}-\mathrm{CSF}$ & None & CP-ATG (52) & 2.0 & $0(0)$ & 85 & NA & 90 & NA \\
\hline $\begin{array}{l}\text { Moore et al. } \\
2019^{53}\end{array}$ & 35 & 37 & 6.9 & 57 & NA & $\mathrm{CP}+\mathrm{G}-\mathrm{CSF}$ & None & BEAM-ATG (35) & 3.0 & $0(0)$ & 91 & 86 & 73 & 60 \\
\hline
\end{tabular}

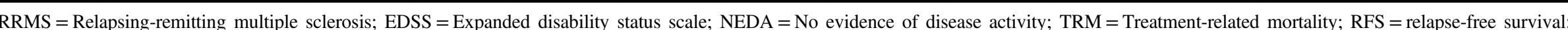

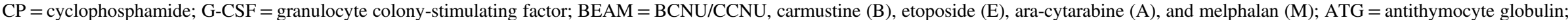
Alem = alemtuzumab; $\mathrm{BU}=$ Busulfan; $\mathrm{IMS}=$ immunomagnetic selection; NA = not available. 
in these various studies were heterogeneous: some exclusively including relapsing patients, while others offered therapy to patients who transitioned to the progressive phase of their disease. The baseline EDSS, disease duration, and follow-up were also variable. Importantly, treatment protocols vary widely. The mobilization regimens were not identical, and only two cohorts used immunomagnetic stem cell selection. It has been argued that the role of ex vivo CD34-positive selection is most useful with higher intensity regimens, such as those containing busulfan, due to the greater immune depletion induced by the conditioning regimen. ${ }^{45}$ In all studies, rates of NEDA are higher than with any current DMT. The rate of inflammatory activity by means of new MRI or clinical relapses is low; however, in the busulfan-containing protocol, there was complete cessation of inflammatory activity for the entire length of follow-up, as high as 14 years in some patients. ${ }^{50}$ In this cohort, there was continued disease progression in seven of the patients $(30 \%)$ who had entered into the progressive phase of their disease despite the lack of ongoing inflammatory activity, but did so early and then stabilized, suggesting carryover of the neurodegenerative damage that resulted from the disease before the AHSCT. In other cohorts that included conditioning regimens other than busulfan, this phenomenon of EDSS progression in patients who already entered the progressive phase was also observed, in addition to EDSS stabilization, and even improvement for a proportion of patients who had not entered the progressive phase. ${ }^{49,51,68}$ However, in the regimens utilizing CP and ATG conditioning, which still attain NEDA rates higher than conventional MS therapies, patients were more likely to have recurrence of inflammation, indicating the lack of a durable response. One would hope that after a successful AHSCT, there would be no need for further DMT and a healthy immune tolerance state to the disease has been accomplished.

\section{Additional Outcome Measures of Treatment Response}

In addition to the standard clinical and MRI measures, biochemical and patient-centered outcomes are important indicators of effective treatment response for patients with MS who have undergone AHSCT. Since the mid-2000s, biochemical analysis of patients with MS who underwent myeloablative conditioning followed by AHSCT revealed that the reconfigured immune system is tolerant, with reduced memory T-cells that potentially contribute autoreactivity, yet diverse, with an increased T-cell receptor repertoire. ${ }^{69,70}$ More recent biomarkers have focused on evidence of neuron damage which occurs in both inflammatory and neurodegenerative phases of MS. NfL is an intermediate filament providing structural support for axonal cytoskeleton. NfL would be a useful tool within the armamentarium of clinical predictor methods in MS for the additional reason than CSF and serum levels appear correlated. ${ }^{71}$ High levels of serum NfL in patients with MS have been implicated in greater 10-year brain atrophy, higher EDSS scores, and higher levels of patient fatigue as quantified by higher scores on a validated patient-reported questionnaire, the modified Fatigue Impact Scale (mFIS). ${ }^{30}$ Fatigue is a highly reported symptom in patients with MS, which impacts quality of life, and may be partially influenced by inflammatory disease activity. ${ }^{72,73}$ Quality of life and patient-reported outcome indices have gained attention as complementary measures to MRI and EDSS since they have been correlated with neurologic disease and support patient-centered care. ${ }^{74,75}$ Understanding of the immunologic markers of treatment response, biochemical evidence of neural damage, and investigation of patient-centered outcomes such as fatigue are important outcomes measures for patients with MS who are to be treated with AHSCT.

Our group has completed post hoc analyses on available data and samples from the 24 patients included in this study investigating both patient-centered and biochemical outcomes. Fatigue is one of the most reported symptoms in patients with MS, $87 \%$ of patients in the Canadian AHSCT study endorsed fatigue with median mFIS scores of 36. Six months after AHSCT, the average mFIS score was reduced to 25.5, which remained low at 23 throughout the 36-month follow-up, a $36 \%$ reduction in fatigue scores. ${ }^{76}$ Additionally, we found that prior to AHSCT patients had high levels of serum NfL. The serum level dropped by $54 \%$ within the first year following AHSCT to a level similar to noninflammatory controls and the reduction was durable. ${ }^{77}$ Six of the seven patients who developed sustained EDSS progression despite the AHSCT had the highest pretreatment NfL levels, suggesting that these patients had the most advanced disease in the first place, and that sustained progression is potentially a manifestation of ongoing neurodegeneration due to prior extensive MS-induced damage to the CNS. The utility of NfL and other biomarkers on prognosis and activity of MS requires further study to determine generalizability and reproducibility. Determining the role of AHSCT in the treatment spectrum for MS requires careful investigation of not only standard clinical and radiologic tools that compose NEDA, but also a focus on patientcentered outcomes, such as fatigue, and importantly identifying patients who may be at most risk of aggressive MS, and thus benefit the most from AHSCT, and novel biomarkers such as NfL may potentially be a useful tool in determining these patients.

\section{Future Challenges}

Patients with aggressive MS are at risk for serious, debilitating, neurological impairment if not appropriately treated starting early in the course of their disease. ${ }^{78}$ The potential risk to benefit ratio of AHSCT must be weighed carefully considered knowing that severe impairment would otherwise ensue when leaving aggressive MS activity unchecked.

The specific role of AHSCT still needs to be further evaluated. In a recent position statement from the American Society of Blood and Marrow Transplantation, a panel of experts in AHSCT and MS endorsed the use of this treatment modality for patients with aggressive MS who are refractory to treatment and at high risk of future disability, insomuch as to recommend AHSCT be considered a standard of care. ${ }^{41}$ Certain newer induction agents, such as alemtuzumab or cladribine, have strong and durable immune-suppressive effects and may delay MS activity, in some to an acceptable degree. However, in those with ongoing inflammatory events or progression, the use of AHSCT is often considered, but due to the prolonged immunosuppressive action of both alemtuzumab and cladribine, care should be used to allow a washout before proceeding with stem cell mobilization. The efficacy of any of MS treatment often depends on how early it is introduced. Randomized controlled trials comparing AHSCT with the newer best standard of care treatments have already started. ${ }^{52}$ Studies are needed to compare the different conditioning regimens as well as the role of ex vivo lymphodepletion. Centers should participate in trials or contribute to registries to 
determine longer term safety, and durability, of AHSCT regimens. As MS patient profiling becomes more precise with better neuroimaging, laboratory or clinical biomarkers, such as NfL, distinguishing which patients have a poorer prognosis and more aggressive disease, patients need not waste time trying, and failing, other DMTs and risking permanent disease progression. ${ }^{79}$

AHSCT is a highly efficacious and relatively safe treatment for early aggressive MS when performed in specialized centers that choose the subpopulation of patients that are least likely to experience toxicity and who will gain the most benefit. The most appropriate candidates are generally younger, such as under the age of 40, free of concerning comorbidities, and demonstrate aggressive early disease with active clinical or radiologic relapses despite treatment along with early progression. Well-conducted randomized trials and registry surveillance are needed to determine if high intensity containing regimens with busulfan attain durable NEDA and plateau progression in other centers. The burden of disease from MS is high. In patients with aggressive disease, including some with progression, resetting the immune system with AHSCT may fix MS.

\section{Disclosures}

Dr. Bose reports no disclosures.

Dr. Thebault reports no disclosures.

Dr. Atkins has received grants from the Multiple Sclerosis Scientific Research Foundation and non-financial support from Amgen Canada.

Dr. Freedman has received personal fees from Genzyme, Merck Serono, Bayer, Biogen Idec, Teva Canada Innovation, Opexa, Novartis, and Chugai.

\section{Statement OF AUTHORShIP}

GB: design and conceptualized study; performed literature review and analyzed the data; drafted the manuscript for intellectual content. SDXT: interpreted the data; drafted and revised the manuscript for intellectual content. HLA: interpreted the data; revised the manuscript for intellectual content. MSF: design and conceptualized the study; analyzed the data; drafted and revised the manuscript for intellectual content.

\section{REFERENCES}

1. Multiple Sclerosis International Federation. Atlas of MS 2013: Mapping multiple sclerosis around the world. London: Multiple Sclerosis International Federation; 2013. Available at: http:// www.msif.org/wp-content/uploads/2014/09/Atlas-of-MS.pdf.

2. Public Health Agency of Canada. Multiple sclerosis, crude prevalence rate. Canadian Chronic Disease Surveillance System (CCDSS). Ottawa: Public Health InfoBase; 2015. Available at: https://health-infobase.canada.ca/ccdss/data-tool/.

3. Marrie RA, Yu N, Blanchard J, Leung S, Elliott L. The rising prevalence and changing age distribution of multiple sclerosis in Manitoba. Neurology. 2010;74(6):465-71.

4. Kingwell E, Zhu F, Marrie RA, et al. High incidence and increasing prevalence of multiple sclerosis in British Columbia, Canada: findings from over two decades (1991-2010). J Neurol. 2015;262(10):2352-63.

5. Marrie RA, Fisk JD, Stadnyk KJ, et al. The incidence and prevalence of multiple sclerosis in Nova Scotia, Canada. Can J Neurol Sci. 2013;40(6):824-31.

6. Gilmour H, Ramage-Morin PL, Wong SL. Health reports multiple sclerosis: prevalence and impact. Ottawa, Canada; 2018. Available from: www.statcan.gc.ca.
7. Harper AC, Harper DA, Chambers LW, Cino PM, Singer J. An epidemiological description of physical, social and psychological problems in multiple sclerosis. J Chronic Dis. 1986;39(4): 305-10.

8. Trisolini M, Honeycutt A, Wiener J, Lesesne S. Global economic impact of multiple sclerosis. Vol. May, Multiple Sclerosis International Federation. London, United Kingdom; 2010. Available from: https://www.msif.org/wp-content/uploads/2014/09/Global_ economic_impact_of_MS.pdf.

9. Asche C V, Ho E, Chan B, Coyte PC. Economic consequences of multiple sclerosis for Canadians. Acta Neurol Scand. 1997; 95(5):268-74.

10. Ernstsson O, Gyllensten H, Alexanderson K, Tinghög P, Friberg E, Norlund A. Cost of illness of multiple sclerosis - A systematic review. PLoS ONE. 2016;11(7):e0159129.

11. Karampampa K, Gustavsson A, Miltenburger C, Kindundu CM, Selchen DH. Treatment experience, burden, and unmet needs (TRIBUNE) in multiple sclerosis: the costs and utilities of MS patients in Canada. J Popul Ther Clin Pharmacol. 2012;19(1): e11-25.

12. Lebrun C. Association between clinical conversion to multiple sclerosis in radiologically isolated syndrome and magnetic resonance imaging, cerebrospinal fluid, and visual evoked potential. Arch Neurol. 2009;66(7):841.

13. Arrambide G, Tintore M, Espejo C, et al. The value of oligoclonal bands in the multiple sclerosis diagnostic criteria. Brain. 2018;141(4):1075-84.

14. Thompson AJ, Banwell BL, Barkhof F, et al. Diagnosis of multiple sclerosis: 2017 revisions of the McDonald criteria. Lancet Neurol. 2018;17(2):162-73.

15. Lassmann $H$, van Horssen J, Mahad D. Progressive multiple sclerosis: pathology and pathogenesis. Nat Rev Neurol. 2012; 8(11):647-56.

16. Ontaneda D, Fox RJ. Progressive multiple sclerosis. Curr Opin Neurol. 2015;28(3):237-43.

17. Kurtzke JF. Rating neurologic impairment in multiple sclerosis: an expanded disability status scale (EDSS). Neurology. 1983; 33(11):1444-52.

18. Kaufman M, Moyer D, Norton J. The significant change for the Timed 25-foot Walk in the multiple sclerosis functional composite. Mult Scler. 2000;6(4):286-90.

19. Cutter G, Baier M, Rudick R. Development of a multiple sclerosis functional composite as a clinical trial outcome measure. Brain. 1999;122(5):871-82.

20. Miller DM, Rudick RA, Cutter G, Baier M, Fischer JS. Clinical significance of the multiple sclerosis functional composite: relationship to patient-reported quality of life. Arch Neurol. 2000; 57(9):1319-24.

21. Trojano M, Paolicelli D, Bellacosa A, Cataldo S. The transition from relapsing-remitting MS to irreversible disability: clinical evaluation. Neurol Sci. 2003;24:s268-70.

22. Gold R, Wolinsky JS, Amato MP, Comi G. Evolving expectations around early management of multiple sclerosis. Ther Adv Neurol Disord. 2010;3(6):351-67.

23. Tremlett H, Yinshan Z, Devonshire V. Natural history of secondaryprogressive multiple sclerosis. Mult Scler J. 2008;14(3):314-24.

24. Noyes K, Weinstock-Guttman B. Impact of diagnosis and early treatment on the course of multiple sclerosis. Am J Manag Care. 2013;19(Suppl. 17):s321-31.

25. Peterson L, Fujinami R. Inflammation, demyelination, neurodegeneration and neuroprotection in the pathogenesis of multiple sclerosis. J Neuroimmunol. 2007;184(1-2):37-44.

26. Weinshenker BG, Rice GPA, Noseworthy JH, Carriere W, Baskerville J, Ebers GC. The natural history of multiple sclerosis: a geographically based study. Brain. 1991;114(2):1045-56.

27. Menon S, Shirani A, Zhao Y, et al. Characterising aggressive multiple sclerosis. J Neurol Neurosurg Psychiatry. 2013;84(11): 1192-8.

28. Freedman MS, Rush CA. Severe, highly active, or aggressive multiple sclerosis. Contin Lifelong Learn Neurol. 2016;22(3):761-84.

29. Rush CA, MacLean HJ, Freedman MS. Aggressive multiple sclerosis: proposed definition and treatment algorithm. Nat Rev Neurol. 2015;11(7):379-89. 
30. Chitnis T, Gonzalez C, Healy BC, et al. Neurofilament light chain serum levels correlate with 10-year MRI outcomes in multiple sclerosis. Ann Clin Transl Neurol. 2018;5(12):1478-91.

31. Brown JWL, Coles A, Horakova D, et al. Association of initial disease-modifying therapy with later conversion to secondary progressive multiple sclerosis. JAMA. 2019;321(2):175.

32. Cohen JA, Coles AJ, Arnold DL, et al. Alemtuzumab versus interferon beta $1 \mathrm{a}$ as first-line treatment for patients with relapsing-remitting multiple sclerosis: a randomised controlled phase 3 trial. Lancet. 2012;380(9856):1819-28.

33. Daniel O. Determining the effectiveness of earLy intensive versus escalation approaches for RRMS (DELIVER-MS). Bethesda (MD): National Library of Medicine (US); 2018. Available at: ClinicalTrials.gov Identifier: NCT03535298; accessed May 24, 2018.

34. Havrdova E, Galetta S, Stefoski D, Comi G. Freedom from disease activity in multiple sclerosis. Neurology. 2010;74(17):S3-7.

35. Hegen H, Bsteh G, Berger T. 'No evidence of disease activity' - is it an appropriate surrogate in multiple sclerosis? Eur J Neurol. 2018;25(9):1107-e101.

36. Sormani MP, Muraro PA, Saccardi R, Mancardi G. NEDA status in highly active MS can be more easily obtained with autologous hematopoietic stem cell transplantation than other drugs. Mult Scler J. 2017;23(2):201-4.

37. Burt RK, Burns W, Hess A. Bone marrow transplantation for multiple sclerosis. Bone Marrow Transplant. 1995;16(1):1-6.

38. Burt RK, Traynor AE. Hematopoietic stem cell transplantation: a new therapy for autoimmune disease. Oncologist. 1999;4:77-83.

39. Sorror ML. Hematopoietic cell transplantation (HCT)-specific comorbidity index: a new tool for risk assessment before allogeneic HCT. Blood. 2005;106(8):2912-9.

40. Friend BD, Tang K, Markovic D, Elashoff D, Moore TB, Schiller GJ. Identifying risk factors associated with worse outcomes in adolescents and young adults undergoing hematopoietic stem cell transplantation. Pediatr Blood Cancer. 2019;e27940.

41. Cohen JA, Baldassari LE, Atkins HL, et al. Autologous hematopoietic cell transplantation for treatment-refractory relapsing multiple sclerosis: position statement from the american society for blood and marrow transplantation. Biol Blood Marrow Transplant. 2019; 25(5):845-54

42. Snowden JA, Badoglio M, Labopin M, et al. Evolution, trends, outcomes, and economics of hematopoietic stem cell transplantation in severe autoimmune diseases. Blood Adv. 2017;1(27):2742-55.

43. Holmqvist AS, Chen Y, Berano Teh J, et al. Risk of solid subsequent malignant neoplasms after childhood Hodgkin lymphomaIdentification of high-risk populations to guide surveillance: a report from the Late Effects Study Group. Cancer. 2019;125(8): 1373-83.

44. Majhail NS, Brazauskas R, Rizzo JD, et al. Secondary solid cancers after allogeneic hematopoietic cell transplantation using busulfancyclophosphamide conditioning. Blood. 2011;117(1):316-22.

45. Atkins HL, Freedman MS. Five questions answered: a review of autologous hematopoietic stem cell transplantation for the treatment of multiple sclerosis. Neurotherapeutics. 2017; 14(4):888-93

46. Sormani MP, Muraro PA, Schiavetti I, et al. Autologous hematopoietic stem cell transplantation in multiple sclerosis. Neurology. 2017;88(22):2115-22.

47. Shevchenko JL, Kuznetsov AN, Ionova TI, et al. Autologous hematopoietic stem cell transplantation with reduced-intensity conditioning in multiple sclerosis. Exp Hematol. 2012;40(11): 892-8.

48. Burman J, Iacobaeus E, Svenningsson A, et al. Autologous haematopoietic stem cell transplantation for aggressive multiple sclerosis: the Swedish experience. J Neurol Neurosurg Psychiatry. 2014; 85(10):1116-21.

49. Burt RK, Balabanov R, Han X, et al. Association of nonmyeloablative hematopoietic stem cell transplantation with neurological disability in patients with relapsing-remitting Multiple Sclerosis. 2015;313(3):275-84.

50. Atkins HL, Bowman M, Allan D, et al. Immunoablation and autologous haemopoietic stem-cell transplantation for aggressive multiple sclerosis: a multicentre single-group phase 2 trial. Lancet. 2016; 388(10044):576-85.
51. Nash RA, Hutton GJ, Racke MK, et al. High-dose immunosuppressive therapy and autologous HCT for relapsing-remitting MS. Neurology. 2017;88(9):842-52.

52. Burt RK, Balabanov R, Burman J, et al. Effect of nonmyeloablative hematopoietic stem cell transplantation vs continued diseasemodifying therapy on disease progression in patients with relapsingremitting multiple sclerosis. JAMA. 2019;321(2):165.

53. Moore JJ, Massey JC, Ford CD, et al. Prospective phase II clinical trial of autologous haematopoietic stem cell transplant for treatment refractory multiple sclerosis. J Neurol Neurosurg Psychiatry. 2019;90(5):514-21.

54. Atkins H, Freedman MS. Immune ablation followed by autologous hematopoietic stem cell transplantation for the treatment of poor prognosis multiple sclerosis. Methods Mol Biol. 2009;549: 231-46.

55. Skerget M, Skopec B, Zontar D, Cernelc P. Mobilization with cyclophosphamide reduces the number of lymphocyte subpopulations in the leukapheresis product and delays their reconstitution after autologous hematopoietic stem cell transplantation in patients with multiple myeloma. Radiol Oncol 2016;50(4):402-8.

56. Rust H, Kuhle J, Kappos L, Derfuss T. Severe exacerbation of relapsing-remitting multiple sclerosis after G-CSF therapy. Neurol - Neuroimmunol Neuroinflammation. 2016;3(2):e215.

57. Hequet $\mathrm{O}$. Hematopoietic stem and progenitor cell harvesting: technical advances and clinical utility. J Blood Med. 2015;55.

58. Bacigalupo A, Ballen K, Rizzo D, et al. Defining the intensity of conditioning regimens: working definitions. Biol Blood Marrow Transplant. 2009;15(12):1628-33.

59. Nash RA. High-dose immunosuppressive therapy and autologous peripheral blood stem cell transplantation for severe multiple sclerosis. Blood. 2003;102(7):2364-72.

60. Samijn JPA, te Boekhorst PAW, Mondria T, et al. Intense T cell depletion followed by autologous bone marrow transplantation for severe multiple sclerosis. J Neurol Neurosurg Psychiatry. 2006;77(1):46-50.

61. Hawkey CJ, Allez M, Clark MM, et al. Autologous Hematopoetic Stem Cell Transplantation for Refractory Crohn Disease. JAMA. 2015;314(23):2524.

62. Rice CM, Mallam EA, Whone AL, et al. Safety and feasibility of autologous bone marrow cellular therapy in relapsing-progressive multiple sclerosis. Clin Pharmacol Ther. 2010;87(6):679-85.

63. Harrison DM, Gladstone DE, Hammond E, et al. Treatment of relapsing-remitting multiple sclerosis with high-dose cyclophosphamide induction followed by glatiramer acetate maintenance. Mult Scler J. 2012;18(2):202-9.

64. Traboulsee A, Arnold D, Bar-Or A, et al. Ocrelizumab No Evidence of Disease Activity (NEDA) status at 96 weeks in patients with relapsing multiple sclerosis: analysis of the Phase III double-blind, double-dummy, interferon beta-1a-controlled OPERA I and OPERA II studies (PL02.004). Neurology. 2016;86(Suppl. 16 ): PL02.004.

65. Mancardi GL, Sormani MP, Gualandi F, et al. Autologous hematopoietic stem cell transplantation in multiple sclerosis A phase II trial. Neurology. 2015;84(10):981-8.

66. Muraro PA, Pasquini M, Atkins HL, et al. Long-term outcomes after autologous hematopoietic stem cell transplantation for multiple sclerosis. JAMA Neurol. 2017;74(4):459.

67. Nash RA, Hutton GJ, Racke MK, et al. High-Dose Immunosuppressive Therapy and Autologous Hematopoietic Cell Transplantation for Relapsing-Remitting Multiple Sclerosis (HALT-MS). JAMA Neurol. 2015;72(2):159.

68. Shevchenko JL, Kuznetsov AN, Ionova TI. Long-term outcomes of autologous hematopoietic stem cell transplantation with reduced-intensity conditioning in multiple sclerosis: physician's and patient's perspectives. Ann Hematol. 2015;94(7):1149-57.

69. Muraro PA, Douek DC, Packer A, et al. Thymic output generates a new and diverse TCR repertoire after autologous stem cell transplantation in multiple sclerosis patients. J Exp Med. 2005; 201(5):805-16.

70. Gosselin D, Rivest S. Immune mechanisms underlying the beneficial effects of autologous hematopoietic stem cell transplantation in multiple sclerosis. Neurotherapeutics. 2011;8(4):643-49. 
71. Dalla Costa G, Martinelli V, Sangalli F, et al. Prognostic value of serum neurofilaments in patients with clinically isolated syndromes. Neurology. 2019;92(7):e733-41.

72. Janardhan V, Bakshi R. Quality of life in patients with multiple sclerosis: the impact of fatigue and depression. J Neurol Sci. 2002;205(1):51-58.

73. Rottoli M, La Gioia S, Frigeni B, Barcella V. Pathophysiology, assessment and management of multiple sclerosis fatigue: an update. Expert Rev Neurother. 2017;17(4):373-9.

74. Raffel J, Wallace A, Gveric D, Reynolds R, Friede T, Nicholas R. Patient-reported outcomes and survival in multiple sclerosis: a 10-year retrospective cohort study using the Multiple Sclerosis Impact Scale-29. Basu S, editor. PLOS Med. 2017;14(7):e1002346.
75. Khurana V, Sharma H, Afroz N, Callan A, Medin J. Patient-reported outcomes in multiple sclerosis: a systematic comparison of available measures. Eur J Neurol. 2017;24(9):1099-107.

76. Bose G, Atkins HL, Bowman M, Freedman MS. Autologous hematopoietic stem cell transplantation improves fatigue in multiple sclerosis. Mult Scler J. 2018;1-9.

77. Thebault S, Tessier D, Lee H, et al. High serum neurofilament light chain normalises after haematopoietic stem cell transplant for Ms. Neurol - Neuroimmunol Neuroinflammation. 2019;6:e598.

78. Atkins H. Stem cell transplantation to treat multiple sclerosis. JAMA. 2019;321(2):153.

79. Freedman MS. 'Time is brain' also in multiple sclerosis. Mult Scler J. 2009;15(10):1133-34. 